\title{
Role of Management Control Systems in Quality, Innovation and Organizational Performance in Portugal SMES Companies
}

\author{
Marina Godinho Antunes* \\ Lisbon Accounting and Business School \\ Lisbon Polytechnic Institute, Avenida Miguel Bombarda \\ 20, 1069-035 Lisboa, Portugal \\ maantunes@iscal.ipl.pt \\ Joaquín Texeira Quirós \\ Faculty of Economics and Business \\ University of Extremadura, Spain \\ Universidade Autónoma de Lisboa \\ 1169-023 Lisboa, Portugal \\ jtexeira@unex.es \\ Maria do Rosáirio Texeira Fernandes Justino \\ Lisbon Accounting and Business School \\ Lisbon Polytechnic Institute, Avenida Miguel Bombarda \\ 20, 1069-035 Lisboa, Portugal \\ mrjustino@iscal.ipl.pt
}

Received 30 June 2016

Revised 31 December 2016

Accepted 18 January 2017

Published 16 March 2018

\begin{abstract}
The purpose of this research is to analyze the relationship between management control systems, total quality management (TQM) and innovation, and also the effects of management control systems in the organizational performance. The research was developed based on a conceptual model designed to analyze these dimensions. The data were obtained through an online questionnaire, sent to small and medium-sized Portuguese companies, having been conducted the study based on responses received from 287 valid questionnaires, and using a multivariate statistical analysis for the statistical development. The findings indicate that nonfinancial indicators provide innovation strategies of products and processes. However, the financial indicators only provide the innovation strategies of processes. It is also verified that only non-financial indicators provide equally the implementation of TQM practices. The results also show that financial indicators only provide an improvement in the financial results of the organization, while the non-financial indicators also improve its operational performance.
\end{abstract}

Keywords: Total quality management; innovation; management control systems; organizational performance. 


\section{Introduction}

Total Quality Management (TQM) has emerged in recent decades as one of the references of management practices. The TQM recognition as a competitive advantage has been widely spread, being a concept that companies cannot ignore at all. Many of the researches that have focused on the effects of TQM over the competitive advantage have shown that its presence leads to improved performance and increased competitiveness [Powell (1995); Anderson and Sohal (1999); Lee et al. (1999); Terziovski and Samson (1999); Zhang (2000); Texeira-Quirós and Justino (2013); Texeira-Quirós et al. (2013); Ebrahimi and Sadeghi (2014)]. On the other hand, innovation has received a considerable attention of numerous researchers by having a crucial role which allows to ensure a more sustainable competitive advantage in the market competition [Damanpour (1991); Prajogo and Sohal (2001); Dooley and O'Sullivan (2007); Tadesse and Osada (2010)].

Organizations have come to recognize that the quality concept must be applied to production processes to lead to products quality and cost minimization [Chenhall (1997)]. However, TQM does not refer only to quality, because productivity, reduction of times, flexibility and profitability are also extremely important performance measures in a TQM program [Pegels (1994)]. It is from this perspective that management control systems assume particular relevance, once the performance indicators allow to study the causality relationships associated with the implementation of TQM practices. The advantages with the cost reduction and the increase of productivity and profitability provide the desired results for any organization that wishes to be successful [Brah et al. (2002)].

Many organizations implement various tools of planning and management control in order of these tools assisting in their performance improvement. However, there is still little evidence of the effectiveness of these tools in the results obtained from the organizations. The main limitation of these investigations seems based on the difficulty in obtaining data that allow to prove the causality relationship between the analyzed indicators and the obtained results. For this reason, the performance measurement systems assume a role of great importance in the study of this topic and for the achievement of the expected conclusions, to the extent that allow the collection and processing of company data.

Management control systems provide information through financial and nonfinancial indicators, and this information assumes great importance because it provides the basis for manager's decision-making in a short, medium and long term, revealing itself essential for the organization's success. Performance measurement systems assume, therefore, a key role in the strategic definition of the organization because they provide value creation associated with the strategic objectives [Ittner and Larcker (1998)]. Several factors such as the phenomenon of globalization, the effect of some macroeconomic variables [Mucharreira and Antunes (2015)], an evident competitiveness increasingly aggressive of the markets, the new management practices, the development of technology, a growing need to innovate products and services, among others, have led to an increased focus on the performance measurement systems of companies. At an internal level of the company, it is also crucial 
that the quality of the obtained information by the managers as well as that information is available in a useful time.

This research aimed to relate the management control systems with TQM and innovation, emphasizing the importance of financial and non-financial information provided by the management control systems in the success of the TQM implementation and innovation programs, and the consequent effects of the management control systems in organizational performance of 287 small and medium-sized Portuguese companies. As mentioned before, in addition to the implementation of TQM and innovation, there is a whole handling information process based on planning and control functions of the organizations that will show whether the respective programs were successful or not.

This paper is organized as follows: Sec. 2 contains the theoretical framework with a brief review of the literature and the relevance of the research topic. In Sec. 3, the empirical research with the sample characterization, the research hypotheses, the conceptual model and the methodology used in data processing are described. At last, in Sec. 4, the main conclusions and contributions of this research are given.

\section{Theoretical Framework}

\subsection{The relevance of the research}

Several studies have been conducted based on TQM approaches and many of the findings have highlighted the various benefits that their practices have provided to the organizations that implement them. Previous researches have shown positive results among the TQM practices and quality levels obtained [Flynn et al. (1995); Ahire et al. (1996); Terziovski and Samson (1999); Prajogo and Sohal (2003); Costa and Lorente (2004); Arumugam et al. (2008)]. However, other researchers have issued dissenting opinions by stating that although some of these organizations had been successful in implementing these measures, others did not achieve any competitive advantage or enhanced the organization's performance [Agus and Abdullah (2000); Han et al. (2007)]. Some authors have emphasized that the problem may be in the form of TQM practices implementation, and also in the methods of measurement and evaluation of these practices, since its implementation reveals itself a complex and difficult process and its advantages are not easy to be verified [Hackman and Wageman (1995)].

With the effect of globalization, organizations have been under increasing pressure to reduce production costs and increase quality. It is in this context that the management control systems are presented as an extremely useful tool because they will allow the collection and processing of financial and non-financial information. In addition to providing the quantitative information, the management control systems also allow to interpret the meaning of that information, and that knowledge will provide decision-making to improve the organization's performance.

From another perspective, in recent decades, the theme of innovation has taken the attention of many researchers and professionals, having considered innovation as a strategic driver to take advantage of new opportunities and protect knowledge 
assets [Damanpour (1987); Teece (2000); Hurmelinna-Laukkanen et al. (2008)]. Innovation plays a key role by providing unique products and services, creating more value than which was previously recognized and by setting barriers to the entry of new competitors [Lloréns-Montes et al. (2005)]. All organizations have their survival as their main objective which is successful and achieves quick growth in the market. Under this view, innovation is the main element that forms the basis of these factors, being considered as an essential point not only for value creation, but also for sustaining competitive advantage. Innovation is not only important for concerning the introduction of a new product or service in the market, but also of great relevance enabling organizations to be more efficient in their operations to identify and quickly adjust to changes in business contexts [Din and Cheema (2013)].

Several studies have examined the relationship between TQM and innovation [Bossink (2002); Prajogo and Sohal (2003, 2004, 2006); Singh and Smith (2004); Hoang et al. (2006)]. In the existing literature, two opposing ideas are found: on the one hand, there is a school of thought that argues that the TQM supports innovation, suggesting that organizations that implement TQM are well succeeded in innovation. On the other hand, there is another line of reasoning that argues that the TQM can even be a factor preventing innovation [Hoang et al. (2010)], and other studies have shown results that lead to still reject a positive relationship between TQM and innovation [Tidd et al. (1997); Slater and Narver (1998)].

Based on these assumptions, we considered important to analyze in detail the financial and non-financial indicators that more accurate and useful information can provide to the organizations that use them, in order to measure, evaluate and to support in their strategies.

\subsection{Management control systems}

Organizations seek to improve their competitiveness by implementing management strategies oriented to quality and innovation, using performance measurement systems that include a wide range of financial and non-financial measures [Strives et al. (1998)]. According to Hoque [2004], the simultaneous use of financial and nonfinancial measures leads managers to pay more attention to critical success factors such as quality, service, time, reliability, innovation and customer's needs. Following the great importance that the management control systems have gained in recent decades, there has been a great interest in the use of financial and non-financial performance measures as well as in the results obtained by combining these two types of measures [Ittner and Larcker (1997, 1998, 2001); Keating (1997); Strives et al. (1998)]. The strong competition in the markets has led organizations to implement strategies and management systems to address the shortcomings experienced by managers in the information provided by existing financial measurement systems and its traditional perspective of short term. For example, some studies about quality have mentioned that the TQM implementation requires greater emphasis on non-financial performance measures, such as quality and customer satisfaction. The issue that is verified states that the financial measures do not appear so efficient in the measurement of the intermediate effects of the production process. 
As such, how much greater the level of implementation of TQM is in the organization, further monitoring will be required and for this reason, more non-financial performance measures will be used [Ittner and Larcker (1995)].

Previous studies also highlighted the positive relationship verified between the management control systems, innovation and performance [Dávila (2000)], as well as the need of the organizations for the implementation of the management control systems to ensure the effectiveness of the innovation [Shields and Young (1994); Simons (1995)]. According to Chenhall [2003], the management control systems have evolved from an approach fundamentally based on quantitative and financial information to a new approach that includes other kinds of information, namely, market information, information concerning the customers, competitors, nonfinancial information related to the production process, forecasts, as well as a wide range of support mechanisms and informal, social and individual control. This evolution is directly related with innovations that have been implemented in the structures and operations of the business units as well as due to new management philosophies adopted by these organizations, such as, just-in-time, flexible production or TQM [Perera et al. (1997)].

The developments verified in the business contexts have originated a change in the way how organizations manage their activity. The organization's performance depends on the quality of decisions taken by managers, and these decisions are connected with a constant need for information that helps to ensure the rational management of resources and strategies in the organizations.

\subsection{Total quality management}

TQM has come to be recognized as a tool which allows to obtain a significant competitive edge in the global market. Some of the most frequent topics mentioned in various definitions suggested for TQM are related to continuous improvement, the customer orientation, the employee autonomy and management commitment, stressing also that the interests of customers, employees, suppliers, competitors and all large-scale society should be considered.

In extant literature, so many TQM definitions are presented which often lead to the conclusion that each author must have his own definition and each organization will have its own way of implementing it [Watson and Korukonda (1995)]. In the context of business, the quality was initially described as good properties of goods and services. However, the concept of product and service quality has gained great importance and new contours, extending its scope to the entire organization. The definition of quality which aims to meet or exceed customer expectations has become an ideology that leads to the pursuit of customer satisfaction. This means that it works as a starting point of the organization's actions quality, targeting the practical applications of quality improvement for that ideology [Savolainen (1999)]. According to this author, the ideological core of the quality concept implies the goal of good quality or excellence for the customer. Thus, the ideology of quality management can be characterized as the intention of improving the organization's competitiveness, making the actions allocated to the quality progress on the path of continuous 
improvement to achieve the customer satisfaction. Thus, the goal will be the improvement of the efficiency and flexibility of the entire business.

TQM has been accepted by managers as a change in quality management approach [Arumugam et al. (2009)], playing a key role in the development of management practices [Prajogo and Sohal (2003); Hoang et al. (2006)]. Many researchers suggest TQM as an approach to improve the efficiency, flexibility and competitive business in order to meet the customer requirements [Oakland (1993)]. Other authors refer it as a source of sustainable competitive advantage for business organizations [Terziovski (2006)], and still others indicate TQM as a way to achieve excellence, creating an attitude of "do it right" at the first time, acquiring efficient business solutions [Mohanty and Behera (1996)].

\subsection{Innovation}

In recent decades, the theme of innovation has attracted the attention of many researchers and practitioners, having considered the innovation as a strategic driver to take advantage of new opportunities [Damanpour (1987); Teece (2000); Hurmelinna-Laukkanen et al. (2008)]. Innovation plays a key role by providing unique products and services, creating more value than which was previously recognized and by setting barriers to the entry of new competitors [Lloréns-Montes et al. (2005)]. While some studies have focused only on a certain type of innovation, such as process innovation, in the case of Abrunhosa et al. [2008], or product innovation, in the case of Prajogo and Sohal [2004], other researchers have explored the process innovation and product innovation, such as the studies of Feng et al. [2006] and Martínez-Costa and Martínez-Lorente [2008]. All organizations have their survival as their main objective which is successful and achieves a quick growth in the market. From this perspective, innovation can be considered as the main element that serves as the basis of these factors, being considered as a crucial point not only for value creation, but also for sustaining competitive advantage.

In the actual literature, several innovation definitions can be found. Damanpour [1991] defines the innovation as everything that is new to the business and which may consist of a system, a policy, a process, a product or service and has been considered as a tool for the organization's success. Lafley and Charan [2008] refer to innovation as a new idea which is realized in benefits, revenues and profits. On the other hand, Crossan and Apaydin [2010] gave a more comprehensive definition of the concept, featuring innovation as a production or adoption, assimilation and exploitation of innovative added value in economic and social spheres; renovation and creation of products, services and markets; development of new production methods; and definition of new management systems, being both a process and an outcome.

Innovation refers to the application of new knowledge, ideas, methods and abilities that can generate unique skills and enhance the organization's competitiveness [Andersson et al. (2008)]. In global markets, organizations must have the ability to identify new opportunities, reconfigure and protect technologies, skills, knowledge assets, to achieve a sustainable competitive advantage [Teece (2000)]. According to Kim et al. [2012], it is necessary to understand the kind of innovation and its 
different characteristics, since a certain type of innovation will require that the organization provides answers adjusted to a given situation.

\section{Empirical Research}

\subsection{Conceptual model and definition of research hypotheses}

As mentioned before, several studies have been developed based on the central theme of TQM practices and innovation strategies. However, few have dedicated particular attention to the indicators through which it will be possible to measure the success or failure of these practices. This research aimed to differentiate it from the previous studies by trying to highlight the contribution of management control systems in the organization's activities, and point out what kind of indicators, financial or nonfinancial, are more efficient in the measurement of specific results. Thus, the initial questions and research hypotheses with the appropriate theoretical framework will be now presented, and subsequently, the conceptual model of this research.

Management control systems have been evolving to a new perspective that began to place greater importance to other kinds of information, besides the one which assumes a purely financial dimension, such as market information, concerning to the customers, competitors, and non-financial information related to the production process and provisional information [Chenhall (2003)]. Initially, it was given more importance to financial indicators due to the fact that professionals needed to access information that reflected the economic and financial situation of the organizations. However, with the development of new management practices, other information has become subject of interest by managers, since it identifies the critical success factors, such as quality, service, times, reliability and customer satisfaction [Hoque (2004)].

Similarly, this kind of information could also provide the obtaining of a more direct and timely feedback about the management actions in certain contexts [Barua et al. (1995)], allowing the adoption of immediate corrective measures, if these prove to be necessary [Rees and Sutcliffe (1994)]. Following this point of view, some researchers appeared to advocate the idea that non-financial indicators may assume an importance as significant as the traditional financial indicators [Hoque and James (2000); Kaplan and Norton (2001); Otley (2003); Henri (2006)]. Other studies highlighted the advantages that can be achieved with an efficient combination of both measures [Ittner and Larcker (1997, 1998, 2001); Keating (1997); Strives et al. (1998)]. There are studies that even refer that the higher is the level of implementation of TQM practices, the more the non-financial performance measures will be necessary, because it will require better monitoring and inspection of the production process [Ittner and Larcker (1995)]. On the other hand, there are researchers who argue that there is a clear evidence that non-financial performance measures play an important role in the success of TQM implementation, since the non-financial measures lead to employees' commitment to quality, including them in the organizational actions [Daniel and Reitsperger (1991); Chenhall (1997); Ittner and Larcker (1997)].

Therefore, the analysis of the relationship between management control systems in two distinguished perspectives, a financial perspective and other non-financial, 
and the implementation of TQM practices is considered to be appropriate, which allows to define two research hypotheses:

$\boldsymbol{Q 1}$. Which is the relationship between management control systems and the implementation of TQM practices?

H1a: Management control systems, composed of financial indicators, provide the implementation of TQM practices.

H1b: Management control systems, composed of non-financial indicators, provide the implementation of TQM practices.

According to Henri [2004], management control systems are not entirely based on the tools used in the planning and control of an organization's activities, also being used by the organizations to promote and control the level of innovation, creativity, changes and learning. Some studies emphasized the identified need by organizations to implement management control systems to ensure the effectiveness of innovation strategies [Shields and Young (1994); Simons (1995)]. Management control systems have suffered an evolution from an approach based on quantitative and financial information for a new approach that also includes other non-financial information [Chenhall (2003)], and it is still referred that this development is directly related with innovations that have been implemented in the structures and operations of the business units [Perera et al. (1997)]. Carenys [2012] pointed out another perspective focused on the organization's needs to take advantage of the processes and mechanisms that allow them to create the most favorable conditions for achieving their goals and simultaneously ensure an efficient and effective use of all resources.

Following these studies, it is considered to be relevant to analyze whether there is a relationship between management control systems (considering financial and nonfinancial indicators) and innovation strategies, differentiating, however, innovation into two different perspectives, the products innovation and processes innovation. Thus, the following research hypotheses are pointed:

Q2. Which is the relationship between management control systems and innovation strategies?

H2a: Management control systems, composed of financial indicators, provide product innovation strategies.

H2b: Management control systems, composed of financial indicators, provide process innovation strategies.

H2c: Management control systems, composed of non-financial indicators, provide product innovation strategies.

H2d: Management control systems, composed of non-financial indicators, provide process innovation strategies.

The organization's performance is a reflection of the quality of decisions taken by managers. These decisions are based on an extensive information provided by management control systems and enable a rational management of resources and 
strategies. On the other hand, managers increasingly need useful and timely information due to the constant progress of information technologies, information that is available from the various management control tools. This fact means that the time spent in preparing the quantitative information has to be increasingly smaller, thus freeing managers to the more complex tasks of analysis and interpretation of the information generated by management systems, allowing thus a quicker decisionmaking.

The development of global markets, the importance placed with ever greater evidence in the relationships with the customers, the improvements of quality of products and services, and the improvement of production technologies are the factors used to increase the level of competition between companies. Consequently, management will require measures and performance indicators in all their functional areas, delegating in the management control systems a key role in providing the required information, which, in principle, can be reflected in an improved organizational performance [Ittner and Larcker $(1998,2002)]$. However, it is necessary to highlight that the concept of organizational performance does not translate in a specific definition, because several studies have highlighted the financial performance while others highlight market performance, and still others the operational performance.

In our investigation, the organizational performance from two different perspectives, one operational and other financial, is considered. Thus, starting from the initial research question that intends to analyze the relationship between management control systems, in its financial and non-financial perspective, and the organization's performance, considering in this case, the operational and financial performance, the following research hypotheses were considered:

Q3. Which is the relationship between management control systems and organizational performance?

H3a: Management control systems, composed of financial indicators, provide an improvement in the financial performance of the organization.

H3b: Management control systems, composed of financial indicators, provide an improvement in the operational performance of the organization.

H3c: Management control systems, composed of non-financial indicators, provide an improvement in the financial performance of the organization.

H3d: Management control systems, composed of non-financial indicators, provide an improvement in the operational performance of the organization.

Completed description of the fundamentals took to the construction of the initial issues through the literature review, and it is now possible to outline the proposed research model, as illustrated in Fig. 1.

\subsection{Research description and sample characterization}

This study was based on a quantitative research and defined through a positivist paradigm [Lincoln and Guba (2000)], and has used the questionnaire as an 


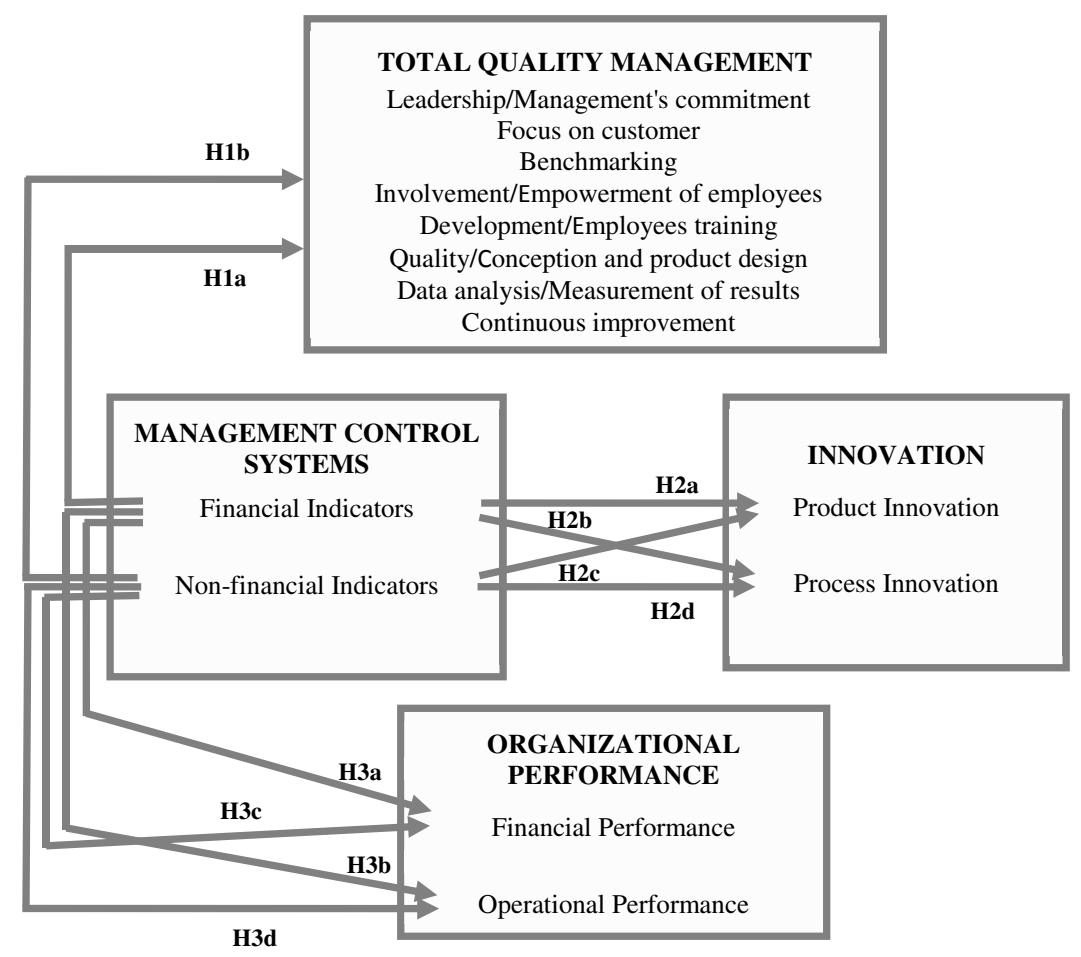

Fig. 1. Conceptual model and research hypotheses.

information gathering tool for statistical processing of data. The questionnaire was designed with closed questions, making use of an ordinal scale, in the specific case, a Likert scale of five points for the evaluation of the opinions of respondents about the dimensions considered. For the characterization of the respondents and organizations, nominal and ordinal scales were used. The questionnaire allowed to collect data of responsible persons from specific areas, concerning to several aspects related with financial and non-financial performance indicators from management control systems, TQM practices and innovation strategies, as well as to obtain characterizing data of companies and respondents, having the respondents selected for each answer, to the assessment of the dimensions that were intended to study, one of the options available on a scale from " $1=$ Strongly Disagree" to " $5=$ Strongly Agree" (for the dimensions of management control systems, TQM, and innovation) or on a scale from " 1 = Extremely Unsuccessful" to " 5 = Extremely Successful" (for organizational performance dimension).

The sample selected for the research was obtained through SABI database (Analysis System of Iberian Balances). Portuguese companies were selected, having been restricted the sample to a certain research criterion in order to achieve a workable number of companies in the current research. Consequently, and since it was intended comparable companies between themselves, small and medium-sized companies were selected, given the typology defined on the Portuguese Decree-Law. Thus, the sample was composed of 946 companies and the invitation for 
participation in the research was done through an email in which a link to access the questionnaire was contained, being the questionnaire the basic instrument for the collection of information that served to the research development. From all companies, 287 questionnaires totally filled out were received, which accounted for $30.34 \%$ of the considered sample.

\subsection{Research methodology}

With respect to the statistical methods used in this study, it was resorted to a multivariate statistical analysis, because in this type of studies that involve a strong statistical component is usual to exist several variables measured or observed in a series of subjects, which are intended to study together. In this type of analysis, there are a variety of available techniques and the choice will focus on a specific technique which is more suitable to the obtained data and to the scientific study objective. The structural equation modeling (SEM) was used, in particular, the confirmatory factor analysis (CFA). In a CFA, we should have prior knowledge of the model and all relevant aspects must be firmly grounded in theory and evidence known. To this end, it has been proved that it is necessary to specify what factors and indicators constituted the model, the items present in each factor, the relationship between the factors and other characteristics inherent to the model rating.

The adjustment index by excellence in models of CFA/SEM is $\chi^{2}$. The acceptance of equality of the matrices occurs in the case where $\chi^{2}$ is sufficiently small and the value of the associated $p$ is greater than 0.05 . However, this index is rarely used as the only decision-maker of the quality of model adjustment, verifying that, in some situations, the distribution of the elements under study does not adjust to the distribution $\chi^{2}$, because its value is influenced by the sample size. As a form to overcome this limitation, it was created a variety of partial indexes. From a list suggested by Brown [2006], the following indexes were used in this study:

- Absolute Index: evaluates the quality of the model with no comparison to other models:

- RMR - Root Mean Square Residual,

- GFI - Goodness of Fit Index,

- AGFI - Adjusted Goodness of Fit Index.

- Parsimonious Index: compensates the artificial improving of the model:

- RMSEA - Root Mean Square Error of Approximation,

- PCFI - Parsimony Comparative Fit Index,

- PGFI - Parsimony Adjusted Goodness of Fit Index.

- Predictive Index: the best model is the one that presents the lowest values in these indexes:

- ECVI - Expected Cross Validation Index,

- AIC - Akaike Information Criterion,

- BIC - Bayes Information Criterion. 
Table 1. Statistics and indexes of adjustment quality.

\begin{tabular}{ll}
\hline Statistic & \multicolumn{1}{c}{ Values of reference } \\
\hline$\chi^{2}$ & The smallest possible \\
The statistical significance associated to $\chi^{2}$ & $\begin{array}{l}\text { The value of } p\left(\chi^{2}\right) \text { should be higher than } 0.05 \\
\text { Less than } 2\end{array}$ \\
$\chi^{2} / d f$ & $\begin{array}{l}\text { Higher than } 0.85 \\
\text { CFI-NFI-GFI-TLI }\end{array}$ \\
Better adjustment nearest to 1 \\
RMSEA & Less than 0.06 \\
& Reject the model if the value is greater than 0.1 \\
RMR & Less than 0.08 \\
& Better adjustment nearest to 0.00 \\
PGFI & Should be greater than 0.6 \\
PCFI & Better adjustment nearest to 1 \\
ECVI-AIC & The smaller the better adjustment \\
\hline
\end{tabular}

Source: Brown [2006].

- Relative Index: evaluates the quality of the model under test with respect to the model with the worst possible adjustment:

- CFI - Comparative Fit Index,

- NFI - Normed Fit Index,

- TLI - Tucker-Lewis Index.

Table 1 aggregates the statistics and indexes commonly used in structural equation applications.

As previously mentioned, the indexes enumerated above constitute a sample of an indexes' variety that have been proposed to, alternatively to $\chi^{2}$ test, estimate the model quality.

\subsection{Analysis and discussion of the results}

\subsubsection{Individual analysis of dimensions for the understanding of final model}

The analysis of the methodological phases that are enunciated below was proposed to assist in the estimation of the final structural model and also to assist in the understanding of the results in each of the proposed dimensions, being each response for each item classified from 1 to 5 , where $1=$ Strongly Disagree, $2=$ Partly Disagree, $3=$ Neither Agree Nor Disagree, $4=$ Partially Agree and $5=$ Strongly Agree or $1=$ Extremely Unsuccessful, $2=$ Unsuccessful, $3=$ Neither Successful Nor Unsuccessful, $4=$ Successful and $5=$ Extremely Successful. First, a descriptive analysis of the items was carried out, followed by an Exploratory Factor Analysis (EFA) to all manifest variables in each of the envisaged dimensions in order to determine whether the research in question should be maintained without any adjustment. After that, a reliability analysis based on Cronbach's Alpha was carried out in Table 2, the correlation between the items of each construct was analyzed, and finally, it was proceeded to a correlation analysis between the constructs.

The use of EFA has its main objective to facilitate the understanding of how items are distributed in different dimensions, considering that the first step in the 
Table 2. Internal consistency of the various dimensions - Cronbach's Alpha.

\begin{tabular}{|c|c|c|}
\hline & Cronbach's Alpha & No. of items \\
\hline \multicolumn{3}{|l|}{ Constructs } \\
\hline Financial indicators & 0.901 & 5 \\
\hline Non-financial indicators & 0.828 & 5 \\
\hline \multicolumn{3}{|l|}{ Dimension } \\
\hline Management control systems & 0.896 & 10 \\
\hline \multicolumn{3}{|l|}{ Constructs } \\
\hline Products & 0.858 & 4 \\
\hline Processes & 0.894 & 4 \\
\hline \multicolumn{3}{|l|}{ Dimension } \\
\hline Innovation & 0.905 & 8 \\
\hline \multicolumn{3}{|l|}{ Constructs } \\
\hline Financial performance & 0.856 & 4 \\
\hline Operational performance & 0.838 & 4 \\
\hline \multicolumn{3}{|l|}{ Dimension } \\
\hline Organizational performance & 0.873 & 8 \\
\hline \multicolumn{3}{|l|}{ Constructs } \\
\hline Leadership & 0.875 & 4 \\
\hline Customer focus & 0.842 & 4 \\
\hline Benchmarking & 0.927 & 4 \\
\hline Employee involvement & 0.851 & 4 \\
\hline Development/training & 0.924 & 4 \\
\hline Quality/product design & 0.859 & 4 \\
\hline Measurement of the results & 0.947 & 4 \\
\hline Continuous improvement & 0.939 & 4 \\
\hline \multicolumn{3}{|l|}{ Dimension } \\
\hline TQM & 0.974 & 32 \\
\hline
\end{tabular}

implementation of an EFA is to observe if the data matrix is liable to factorize [Pasquali (1998)]. To do that, two references are commonly used, namely, the Kaiser-Meyer-Olkin (KMO) criterion and Bartlett's sphericity test [Dziuban and Shirkey (1974)]. The KMO index indicates the level of adequacy of EFA application to the data set, being the value variation between zero and one, also known as the adequacy index of the data to sample, and is a value that indicates the proportion of the items variance that is explained by a latent variable [Lorenzo-Seva et al. (2011)]. In the present investigation, it an EFA was made with the extraction of factors by the method of principal components. With the purpose to ensure the consistency of the instrument that was used, the method based on internal consistency of Cronbach was followed, given the fact that this study uses scales which have been already developed and applied in other research papers. This method allows the evaluation of the reliability of the measurement instrument through a set of items that are expected to measure the same construct or theoretical dimension, assuming that the items in the questionnaire used (measured on a Likert scale from 1 to 5) measure the same construct and are highly correlated [Pestana and Gageiro (2008)]. The closer the Cronbach's alpha value is to 1 , the higher is the internal consistency of the items analyzed. 
Table 3. Bartlett test and Kaiser-Meyer-Olkin test.

\begin{tabular}{lc}
\hline Kaiser-Meyer-Olkin Measure of Sampling Adequacy & 0.947 \\
Bartlett's Test of Sphericity & \\
Approx. Chi-Square & 14670.617 \\
df & 1653 \\
Sig. & 0.000 \\
\hline
\end{tabular}

Table 3 shows that the proposed model has an associated value of KMO equal to 0.947, indicating that there is an excellent correlation between the items that compose the model [Hayton et al. (2004)]. The Bartlett's sphericity test has associated a significance level of 0.000 .

\subsubsection{Results of the $C F A$}

The factorial validity of each dimension and of the final model was computed based on a CFA with recourse to software Amos (V.23, SPSS Inc., Chicago, IL) that was used to calculate the matrices of variance and covariance, and also for the estimation of the causal measurement model of second-order. The CFA method involved a multistep procedure and the estimation of their individual parameters. The estimation was performed by the maximum likelihood (ML) method, by virtue of having the purpose to develop and test the dimensions and the structural model proposed, based on the answers given by respondents in each item. Statistical acceptance of each dimension was made based on the value obtained from the chi-square and indexes listed in Table 1. Given the research objectives, the matrix of variances and covariance of the items of the factors was used in the search of a direct or indirect causal relationship between the items or, in other words, to see if they interacted through correlated paths.

Thus, in Table 4, it is possible to analyze the final results obtained for the different investigation hypotheses, after the appropriate adjustments made to the structural model. It is also important to note that a model can be artificially modified into perfection by the analysis of the modification indexes and, consequently, by the establishment of the trajectories suggested by the indicators.

(a) Results of the research for hypotheses H1a and H1b

Table 5, having the study sample as reference, shows that only the path between the first-order factor "Financial indicators" and the second-order factor "Quality management" reveals not significant ( $p$ value $=0.296>\alpha=0.05$ ) in the modified model,

Table 4. Adjustment indexes obtained from the structural model.

\begin{tabular}{lrccccc}
\hline Hypotheses & \multicolumn{1}{c}{$\chi^{2}$} & $\chi^{2} / d f$ & CFI & PCFI & GFI & RMSEA \\
\hline H1a and H1b & 1802.122 & 2.241 & 0.906 & 0.846 & 0.767 & 0.066 \\
H2a, H2b, H2c and H2d & 163.376 & 1.945 & 0.968 & 0.774 & 0.930 & 0.058 \\
H3a, H3b, H3c and H3d & 215.902 & 2.226 & 0.953 & 0.779 & 0.915 & 0.066 \\
\hline
\end{tabular}


Table 5. Regression weights: Standardized estimates and unstandardized estimates.

\begin{tabular}{lcccc}
\hline & Estimate & SE & CR & $p$ \\
\hline Quality Management $\leftarrow$ Financial Indicators & $\mathbf{0 . 0 7 8}$ & $\mathbf{0 . 0 7 4}$ & $\mathbf{1 . 0 4 6}$ & $\mathbf{0 . 2 9 6}$ \\
Quality Management $\leftarrow$ Non-financial Indicators & 0.487 & 0.085 & 5.724 & $* * *$ \\
\hline
\end{tabular}

Notes: SE — Standardized estimates; Estimate - Unstandardized estimates; $* * *$ is significantly different from zero at the 0.001 level (two-tailed).

Table 6. Regression weights: Standardized estimates and unstandardized estimates.

\begin{tabular}{lccccc}
\hline & SE & UE & SE & CR & $p$ \\
\hline Product innovation $\leftarrow$ Financial indicators & $\mathbf{0 . 1 5 1}$ & $\mathbf{0 . 2 4 4}$ & $\mathbf{0 . 1 4 1}$ & $\mathbf{1 . 7 2 8}$ & $\mathbf{0 . 0 8 4}$ \\
Process innovation $\leftarrow$ Financial indicators & 0.319 & 0.486 & 0.125 & 3.876 & $* * *$ \\
Product innovation $\leftarrow$ Non-financial indicators & 0.287 & 0.413 & 0.134 & 3.076 & 0.002 \\
Process innovation $\leftarrow$ Non-financial indicators & 0.310 & 0.419 & 0.115 & 3.628 & $* * *$ \\
\hline
\end{tabular}

Notes: SE - Standardized estimates; UE - Unstandardized estimates; *** is significantly different from zero at the 0.001 level (two-tailed).

allowing to conclude that hypothesis H1a was not confirmed, being only possible to confirm the hypothesis H1b.

(b) Results of the research for hypotheses H2a, H2b, H2c and H2d

Table 6 shows that, from all the relations in the obtained model, only the factor "Financial indicators" has no statistically significant effect on the factor "products" $(p$ value $=0.084>\alpha=0.05)$, which allows to state that "Management control systems, composed of financial indicators, do not provide product innovation strategies". The remaining hypotheses are verified, namely, the hypotheses H2b, H2c and $\mathrm{H} 2 \mathrm{~d}$.

(c) Results of the research for hypotheses H3a, H3b, H3c and H3d

Through the interpretation of Table 7 , it can be stated that, from the relations established in the simplified model, there are two relationships that did not reveal statistically significant, in this case, trajectories between the factors "Financial indicators" and "Operational performance" $(p$ value $=0.287>\alpha=0.05)$ and between the factors "Non-financial indicators" and "Financial performance"

Table 7. Regression weights: Standardized estimates and unstandardized estimates.

\begin{tabular}{lccccc}
\hline & SE & UE & SE & CR & $p$ \\
\hline Financial performance $\leftarrow$ Financial indicators & & 0.168 & 0.091 & 1.834 & 0.047 \\
Operational performance $\leftarrow$ Financial indicators & & $\mathbf{0 . 0 7 8}$ & $\mathbf{0 . 0 7 3}$ & $\mathbf{1 . 0 6 5}$ & $\mathbf{0 . 2 8 7}$ \\
Financial performance $\leftarrow$ Non-financial indicators & $\mathbf{0 . 1 4 9}$ & $\mathbf{0 . 0 8 5}$ & $\mathbf{1 . 7 4 3}$ & $\mathbf{0 . 0 8 1}$ \\
Operational performance $\leftarrow$ Non-financial indicators & 0.175 & 0.070 & 2.505 & 0.012 \\
\hline
\end{tabular}

Notes: SE - Standardized estimates; UE - Unstandardized estimates; $* * *$ is significantly different from zero at the 0.001 level (two-tailed). 
( $p$ value $=0.081>\alpha=0.05)$. Thus, it is concluded that "Management control systems, composed of financial indicators, do not provide an improvement in the organization's operational performance" and that "Management control systems, composed of non-financial indicators, do not provide an improvement in the organization's financial performance". The other two hypotheses are verified, namely, the hypotheses H3a and H3d.

\section{Conclusions}

\subsection{Main conclusions of the research}

Many companies implement various tools of planning and management control in order to assist the improvement of their performance. However, there is still little evidence of the effectiveness of these tools on the obtained results by the organizations. The main limitation of those previous investigations appears to be based on the difficulty to get the needed data that can prove the causality relationship between the indicators analyzed and the obtained results. For that reason, the performance measurement systems assume an important role in the study of this subject, to the extent that allow the collection and processing of company data. In this way, management control systems provide information through financial and non-financial indicators, information of great importance, because it serves the basis for making decisions of the managers in a short, medium and long terms, and also proving to be essential to the organizations, revealing itself of a major importance to the organization's success.

Based on these assumptions, the present study sought to examine the relationship between several dimensions, namely, management control systems, TQM and innovation, and also the effects of management control systems in the organizational performance. As it was emphasized throughout this study, it proves to be of great importance to assess, measure and monitor the whole process of TQM and innovation implementation, as well as the evaluation of their effects, both in short and long terms in the organizational performance. Based on the issues and the main objectives of this study, initially, some divergences in the literature were shown, not only with regard to the results of several studies developed in recent years, but also concerning the different interpretations of the studied concepts, whereby in this research, a conceptual model that aimed to answer the research questions developed was proposed. The results showed that non-financial indicators provide innovation strategies of products and processes. However, the financial indicators only benefit the innovation strategies concerning the processes. It is also verified that only nonfinancial indicators provide, similarly, the implementation of TQM practices. On the other hand, the results showed that financial indicators only provide an improvement in the financial results of the organization, while the non-financial indicators improve its operational performance.

In fact, as mentioned before, globalization and liberalization of markets, characterized by an intense competition, have created a need in companies to provide them with useful and timely information. Thus, companies have come to rely on a set 
of financial and non-financial performance measures, leading to the emergence of new management practices, assuming competitiveness as a determining factor in the changes in management practices. In order to measure, evaluate and understand the "health" of organizations, managers often use financial indicators that support the analysis of the economic and financial situation of the company. However, the importance of non-financial indicators has been emphasized with particular attention by theorists, being this trend, equally related with the adoption of new management practices [Hoque and James (2000); Kaplan and Norton (2001); Otley (2003); Henri (2006)]. The relationship between the implementation of TQM practices and an increasingly significant emphasis on non-financial performance measures — such as quality and customer satisfaction - has been referred to the studies conducted on this topic.

The findings of this research, concerning the study of these dimensions, are supported in the literature, for example, the investigations of Hoque and James [2000], Kaplan and Norton [2001], Otley [2003] and Henri [2006], who claim that non-financial indicators may assume an importance as significant as the traditional financial indicators. Furthermore, several other studies have pointed out the advantages that could be achieved with an efficient combination of the use of financial and non-financial indicators [Ittner and Larcker (1998, 2001); Strives et al. (1998)].

Researches based on these performance measures assume that the integration of non-financial measures in measurement systems enable managers to a better understanding of the relationships between the various strategic objectives, facilitate communication between the actions of employees and the goals set, and assist in the allocation of resources and prioritization, attending to those strategic objectives [Kaplan and Norton (1996)]. Furthermore, taking into account the definition and implementation of strategies and information systems that emphasize the value creation, it will be possible to align the management processes and internal goals with the external goals of the organization [Ittner and Larcker (2001)].

\subsection{Major contributions of the research}

After having previously enunciated the main conclusions of this research, it is now considered pertinent to mention the main contributions and its implications in the corporation's business. Several previous studies were conducted looking into the issues of the implementation of TQM and innovation, and their effects on business performance. However, this study enriches the literature by filling a gap of some disagreements identified in the previous studies, not only with respect to the ambiguity of the obtained results in those studies, but also in the different interpretations of the concepts studied. This research provides a unique contribution by relating the importance of management control systems with these dimensions, and highlights the evidence of the need of financial and non-financial indicators for evaluation, measurement and monitoring of business activity. Besides that, the studies concerning these dimensions in Portuguese companies are still scarce and there is a lack of knowledge about the characteristics and the reality of Portuguese 
companies, therefore, this study, also in this sense, proved to be an added value for the consistency of this knowledge.

Thus, it is considered that the conclusions of this research contribute very significantly to the assessment of the management control systems, TQM and innovation in Portuguese business, providing a detailed knowledge of Portuguese companies, highlighting the contribution of the management control systems to improve the efficiency and effectiveness of small and medium-sized Portuguese companies.

\section{References}

Abrunhosa, A., Moura, E. and Sá, P. (2008). Are TQM principles supporting innovation in the Portuguese footwear industry? Technovation, 28, 4: 208-221.

Agus, A. and Abdullah, M. (2000). The mediating effect of customer satisfaction on TQM practices and financial performance. Singapore Management Review, 22, 2: 55-75.

Ahire, S., Golhar, D. and Waller, M. (1996). Development and validation of TQM implementation constructs. Decision Sciences, 27, 1: 23-56.

Anderson, M. and Sohal, A. (1999). A study of the relationship between quality management practices and performance in small business. International Journal of Quality 83 Reliability Management, 16, 9: 859-877.

Andersson, M., Lindgren, R. and Henfridsson, O. (2008). Architectural knowledge in interorganizational IT innovation. Journal of Strategic Information Systems, 17, 1: 19-38.

Arumugam, V., Chang, H., Ooi, K. and Teh, P. (2009). Self-assessment of TQM practices: A case analysis. The TQM Journal, 21, 1: 46-58.

Arumugam, V., Ooi, K. and Fong, T. (2008). TQM practices and quality management performance - an investigation of their relationship using data from ISO 9001:2000 firms in Malaysia. The TQM Magazine, 20, 6: 636-650.

Barua, A., Kriebel, C. and Mukhopadhyay, T. (1995). Information technologies and business value: An analytic and empirical investigation. Information Systems Research, 6, 1: 3-24.

Bossink, B. (2002). The strategic function of quality in the management of innovation. Total Quality Management, 13, 2: 195-205.

Brah, S. A., Lee, S. L. and Rao, B. M. (2002). Relationship between TQM and performance of Singapore companies. International Journal of Quality \& Reliability Management, 19, 4: 356-379.

Brown, T. A. (2006). Confirmatory Factor Analysis for Applied Research. Guilford, New York.

Carenys, J. (2012). Management control systems: A historical perspective. International Journal of Economy, Management and Social Sciences, 1, 1: 1-18.

Chenhall, R. H. (1997). Reliance on manufacturing performance measures, total quality management organizational performance. Management Accounting Research, 8, 2: 187-206.

Chenhall, R. H. (2003). Management control systems design within its organizational context: Findings from contingency based research and directions for the future. Accounting, Organizations and Society, 28, 2/3: 127-168.

Costa, M. and Lorente, A. (2004). ISO 9000 as a tool for TQM: A Spanish case study. The Quality Management Journal, 11, 4: 20-31.

Crossan, M. and Apaydin, M. (2010). A multi-dimensional framework of organizational innovation: A systematic review of the literature. Journal of Management Studies, 47, 6: 1154-1191.

Damanpour, F. (1987). The adoption of technological, administrative, and ancillary innovations: Impact of organizational factors. Journal of Management, 13, 4: 675-688. 
Damanpour, F. (1991). Organizational innovation: A meta-analysis of effects of determinants and moderators. Academy of Management Journal, 34, 3: 550-590.

Daniel, S. and Reitsperger, W. (1991). Linking quality strategy with management control systems: Empirical evidence from Japanese industry. Accounting, Organizations and Society, 16, 7: 601-618.

Dávila, A. (2000). An empirical study on the drivers of management control systems design in new product development. Accounting, Organizations and Society, 25, 4/5: 383-410.

Din, C. and Cheema, K. (2013). Strategic change: A study of TQM and Innovation. Management and Administrative Sciences Review, 2, 3: 254-260.

Dooley, L. and O'Sullivan, D. (2007). Managing within distributed innovation networks. International Journal of Innovation Management, 11, 3: 397-416.

Dziuban, C. D. and Shirkey, E. C. (1974). When is a correlation matrix appropriate for factor analysis? Some decision rules. Psychological Bulletin, 81, 6: 358-361.

Ebrahimi, M. and Sadeghi, M. (2014). Quality management and performance: An annotated review. International Journal of Production Research, 51, 18: 5625-5643.

Feng, J., Prajogo, D., Tan, K. and Sohal, A. (2006). The impact of TQM practices on performance a comparative study between Australian and Singaporean organizations. European Journal of Innovation Management, 9, 3: 269-278.

Flynn, B., Schroeder, R. and Sakakibara, S. (1995). The impact of quality management practices on performance and competitive advantage. Decision Sciences, 26, 5: 659-692.

Hackman, J. and Wageman, R. (1995). Total quality management: Empirical, conceptual and practical issues. Administrative Science Quarterly, 40, 1: 309-342.

Han, S., Chen, S. and Ebrahimpour, M. (2007). The impact of ISO 9000 on TQM and business performance. The Journal of Business and Economic Studies, 13, 2: 1-25.

Hayton, J. C., Allen, D. G. and Scarpello, V. (2004). Factor retention decisions in exploratory factor analysis: A tutorial on parallel analysis. Organizational Research Methods, 7, 2: 191-205.

Henri, J. (2004). Performance measurement and organizational effectiveness: Bridging the gap. Managerial Finance, 30, 6: 93-123.

Henri, J. (2006). Organizational culture and performance measurement systems. Accounting, Organizations and Society, 31, 1: 77-103.

Hoang, D., Igel, B. and Laosirihongthong, T. (2006). The impact of total quality management on innovation: Findings from a developing country. International Journal of Quality 8 Reliability Management, 23, 9: 1092-1117.

Hoang, D., Igel, B. and Laosirihongthong, T. (2010). Total quality management (TQM) strategy an organizational characteristics: Evidence from a recent WTO member. Total Quality Management, 21, 9: 931-951.

Hoque, Z. (2004). A contingency model of the association between strategy, environmental uncertainty and performance measurement: Impact on organizational performance. International Business Review, 13, 4: 485-502.

Hoque, Z. and James, W. (2000). Linking balanced scorecard measures to size and market factors: Impact on organizational performance. Journal of Management Accounting Research, 12, 1: 1-17.

Hurmelinna-Laukkanen, P., Sainio, L. and Jauhiainen, T. (2008). Appropriability regime for radical and incremental innovations. RED Management, 38, 3: 278-289.

Ittner, C. and Larcker, D. F. (1995). Total quality management and the choice of information and reward systems. Journal of Accounting Research, 40, 3: 1-34.

Ittner, C. and Larcker, D. F. (1997). Quality strategy, strategic control systems and organisational performance. Accounting, Organizations and Society, 22, 3/4: 293-314.

Ittner, C. and Larcker, D. F. (1998). Are non-financial measures leading indicators of financial performance? An analysis of customer satisfaction. Journal of Accounting Research, 36: $1-35$. 
Ittner, C. and Larcker, D. F. (2001). Assessing empirical research in managerial accounting: A value-based management perspective. Journal of Accounting and Economics, 32, 1: 349-410.

Ittner, C. and Larcker, D. F. (2002). Empirical managerial accounting research: Are we just describing management accounting practice? European Accounting Review, 11, 4: 787-794.

Kaplan, R. and Norton, D. (1996). The Balanced Scorecard: Translating Strategy into Action. Harvard Business School Press, Boston, MA.

Kaplan, R. and Norton, D. (2001). Transforming the balanced scorecard from performance measurement to strategic management: Part I. Accounting Horizon, 15, 1: 87-104.

Keating, S. (1997). Determinants of divisional performance evaluation practices. Journal of Accounting and Economics, 24, 1: 243-274.

Kim, D. Y., Kumar, V. and Kumar, U. (2012). Relationship between quality management practices and innovation. Journal of Operations Management, 30, 4: 295-315.

Lafley, A. and Charan, R. (2008). The Game-Changer: How You Can Drive Revenue and Profit Growth with Innovation. Crown Business, New York.

Lee, T., Adam, E. and Tuan, C. (1999). The convergent and predictive validity of quality and productivity practices in Hong Kong industry. Total Quality Management, 10, 1: 73-84.

Lincoln, Y. and Guba, E. (2000). Paradigmatic controversies, contradictions, and emerging confluences. In Handbook of Qualitative Research, eds. Denzin, N. K. and Lincoln, Y. S., 2nd edn. Sage, CA, Thousand Oaks, pp. 163-188.

Lloréns-Montes, F., Ruiz-Moreno, A. and Garcia-Morales, V. (2005). Influence of support leadership and teamwork cohesion on organizational learning, innovations and performance: An empirical examination. Technovation, 25, 10: 1159-1172.

Lorenzo-Seva, U., Timmerman, M. E. and Kiers, H. A. L. (2011). The Hull method for selecting the number of common factors. Multivariate Behavioral Research, 46, 2: 340-364.

Martínez-Costa, M. and Martínez-Lorente, A. (2008). Does quality management foster or hinder innovation? An empirical study of Spanish companies. Total Quality Management, 19, 3: 209-221.

Mohanty, R. and Behera, A. (1996). TQM in the service sector. Work Study, 45, 3: 13-17.

Mucharreira, P. R. and Antunes, M. G. (2015). Os efeitos das variáveis macroeconómicas no desempenho das organizações: Evidência das pequenas e médias empresas em Portugal. Portuguese Journal of Accounting and Management, 17: 113-143.

Oakland, J. (1993). Total Quality Management: The Route of Improving Performance. Butterworth-Heinemann, Oxford.

Otley, D. (2003). Management control and performance management; whence and whither? British Accounting Review, 35, 4: 309-326.

Pasquali, L. (1998). Princípios de elaboração de escalas psicológicas. Revista Psiquiatria Clínica, 25, 5: 206-213.

Pegels, C. C. (1994). Total quality management defined in terms of reported practice. International Journal of Quality \&3 Reliability Management, 11, 5: 6-18.

Perera, S., Harrison, G. and Poole, M. (1997). Customer-focused manufacturing strategy and the use of operations-based non-financial performance measures: A research note. Accounting Organizations and Society, 22, 6: 557-572.

Pestana, M. H. and Gageiro, J. N. (2008). Análise de Dados para Ciências Sociais - A Complementaridade do SPSS. Edições Sílabo, Lisboa.

Powell, T. (1995). Total quality management as competitive advantage: A review and empirical study. Strategic Management Journal, 16, 1: 15-37.

Prajogo, D. and Sohal, A. (2001). TQM and innovation: A literature review and research framework. Technovation, 21, 9: 539-558. 
Prajogo, D. and Sohal, A. (2003). The relationship between TQM practices, quality performance, and innovation. International Journal of Quality \& Reliability Management, 20, 8: 901-918.

Prajogo, D. and Sohal, A. (2004). The multidimensionality of TQM practices in determining quality and innovation performance: An empirical examination. Technovation, 24, 6: 443-453.

Prajogo, D. and Sohal, A. (2006). The integration of TQM and technology/R\&D management in determining quality and innovation performance. Omega: The International Journal of Management Science, 34, 3: 296-312.

Rees, W. and Sutcliffe, C. (1994). Quantitative non-financial information and income measures: The case of long-term contracts. Journal of Business Finance and Accounting, 21, 3: $331-347$.

Savolainen, T. (1999). Cycles of continuous improvement — Realizing competitive advantages through quality. International Journal of Operations $\&$ Production Management, 19, 11: 1203-1222.

Shields, M. and Young, S. (1994). Managing innovation costs: A study of cost conscious behavior by R\&D professionals. Journal of Management Accounting Research, 6, 1: 175-196.

Simons, R. (1995). Control in an age of empowerment. Harvard Business Review, 73, 2: 80-88.

Singh, P. and Smith, A. (2004). Relationship between TQM and innovation: An empirical study. Journal of Manufacturing Technology Management, 15, 5: 394-401.

Slater, S. and Narver, J. (1998). Customer-led and market-led: Let's not confuse the two. Strategic Management Journal, 19, 10: 1001-1006.

Strives, B., Covin, T., Hall, N. and Smalt, S. (1998). How nonfinancial performance measures are used: Survey of Fortune 500 and Canadian Post 300 executives. Management Accounting, 79, 8: 44-49.

Taddese, F. and Osada, H. (2010). Process techno-innovation using TQM in developing countries empirical study of Deming Prize Winners. Journal of Technology Management $\mathscr{E}$ Innovation, 5, 2: 47-65.

Teece, D. (2000). Managing Intellectual Capital. Oxford University Press, Oxford.

Terziovski, M. (2006). Quality management practices and their relationship with customer satisfaction and productivity improvement. Management Research News, 29, 7: 414-424.

Terziovski, M. and Samson, D. (1999). The link between total quality management practice and organizational performance. International Journal of Quality 85 Reliability Management, 16, 3: 226-237.

Texeira-Quirós, J., Almaça, J. and Justino, M. R. (2013). Nonparametric decision tree: The impact of ISO 9000 on certified and non-certified companies. Intangible Capital, 9, 3: $559-570$.

Texeira-Quirós, J. and Justino, M. R. (2013). A comparative analysis between certified and non-certified companies through the quality management system. International Journal of Quality \& Reliability Management, 30, 9: 958-969.

Tidd, J. Bessant, J. and Pavitt, K. (1997). Managing Innovation Integrating Technological Market and Organizational Change. Chichester, UK: Wiley.

Watson, J. and Korukonda, A. (1995). The TQM jungle: A dialectical analysis. International Journal of Quality \& Reliability Management, 12, 9: 100-109.

Zhang, Z. (2000). Developing a model of quality management methods and evaluating their effects on business performance. Total Quality Management, 11, 1: 129-137.

\section{Biography}

Marina Godinho Antunes is a Professor at the Lisbon Accounting and Business School of the Lisbon Polytechnic Institute. She has a Ph.D. in Financial Economics and Accounting from the University of Extremadura, Spain. Her research interests 
are on the areas of management accounting, cost accounting, quality management, innovation and strategy. She has published papers in scientific journals, presentations and publications in annuals conferences.

Joaquín Texeira Quirós is a Full-Time Professor at the Faculty of Economics and Business of the University of Extremadura (Spain) and at the Autonomous University of Lisbon. He received his Ph.D. from the University of Extremadura in Economics and Business Science. He is a Research Fellow at the Riegos Empresariales, Finanzas y inversiones, Calidad, Turismo y Empresas, which is based at the University of Extremadura. He has published papers in scientific journals, presentations and publications in annuals of seminaries and conferences. His research interests are in the areas of quality management, quality costs, strategy, innovation and quality.

Maria do Rosário Fernandes Justino is a Full-Time Professor at the Lisbon Accounting and Business School of the Lisbon Polytechnic Institute, the Director of the Master in Management Control and Business and the Director of the Management High Degree and Collaborates as a Professor at the Autonomous University of Lisbon in the Management High Degree. She received her Ph.D. from the University of Extremadura (Spain) in Economic Science and Business. She is a Research Fellow at the SOCIUS - Research Centre in Economic and Organizational Sociology, which is based at the Lisbon School of Economics and Management of the University of Lisbon. She has published papers in scientific journals, presentations and publications in annuals of seminaries and conferences. Her research interests are in the areas of quality management, quality costs, strategy, innovation and quality. 